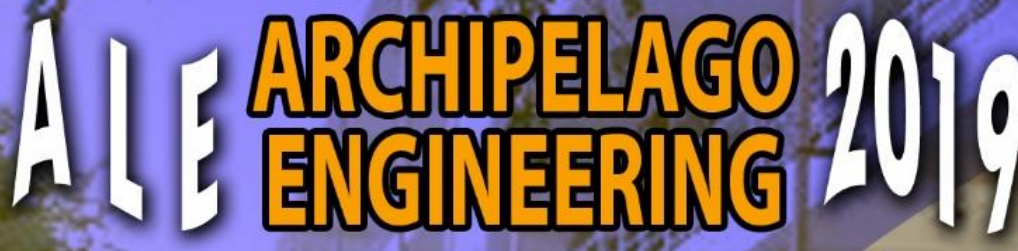

Fakultas Teknik Universitas Pattimura

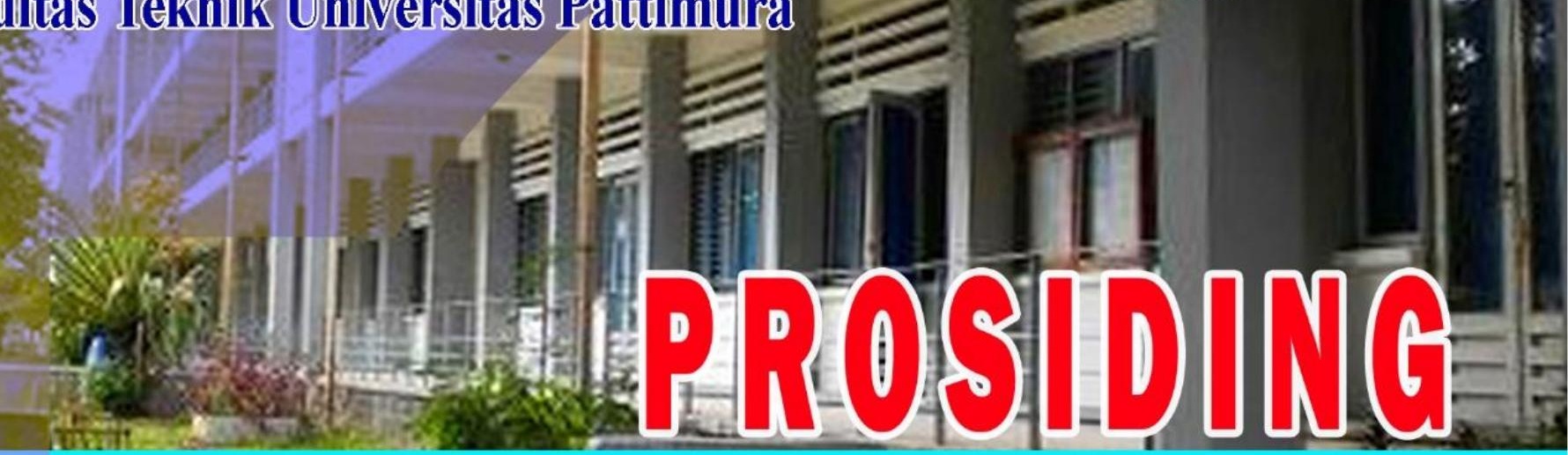

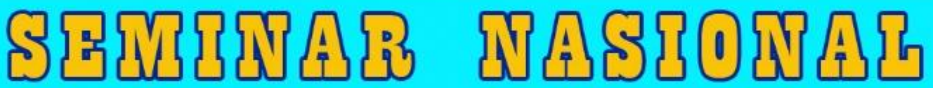

\section{ISSN: 2620-3995}

FAKULTAS TEKN IK UNIVERSITAS PATTIMURA KAMPUS POKA AMBON 10 APRIL 2019

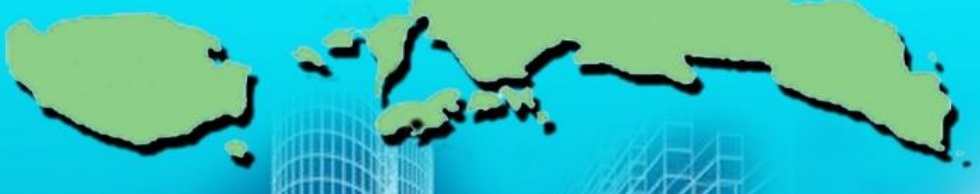

Hons

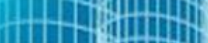

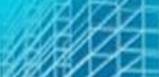

$102=0$
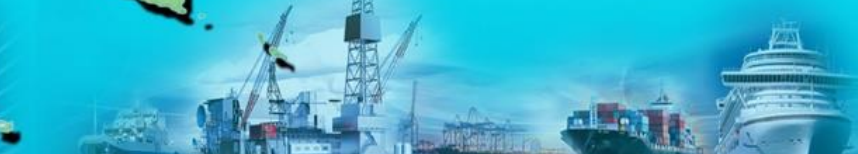

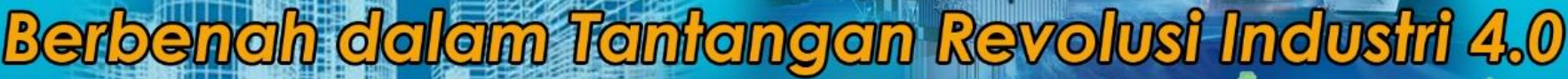

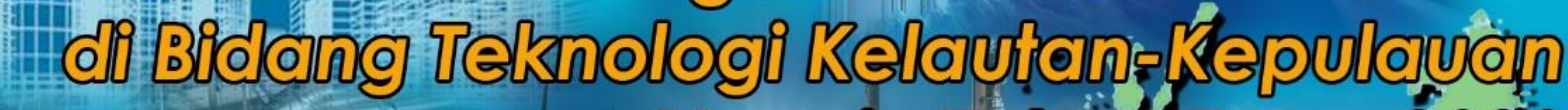

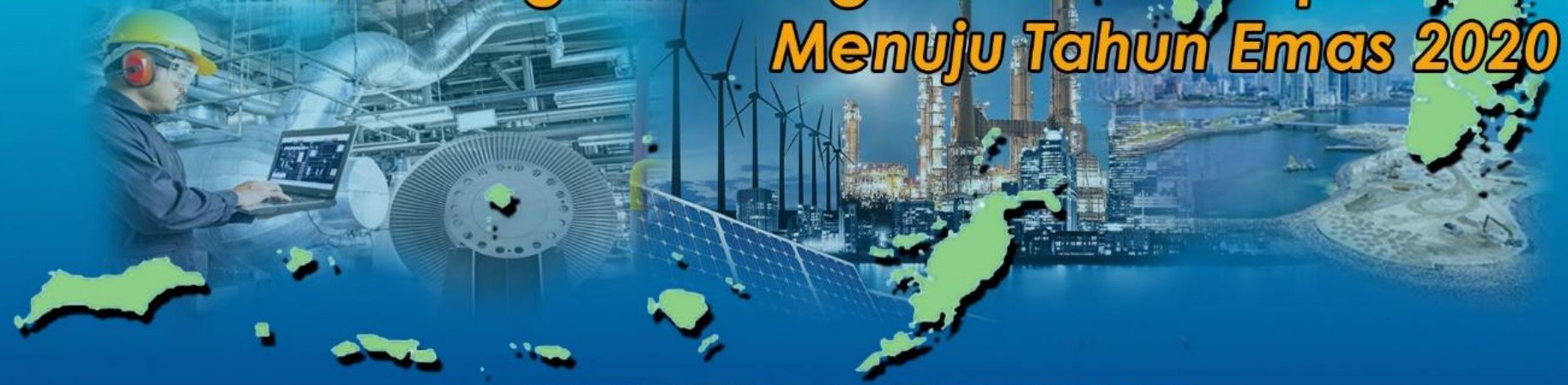

FARUITAS TREIRINIR

UINIVIRISITRAS PATTLIIIIURRA

ANBBON

2(1)129 

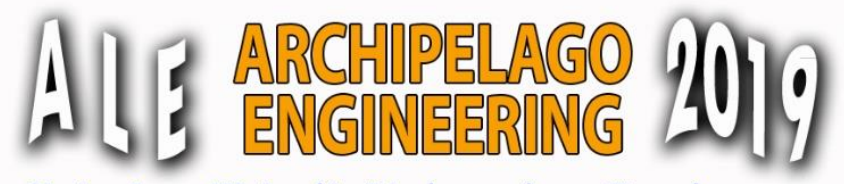

ISSN: 2620-3995

Fakultas Teknik Universitas Pattimura
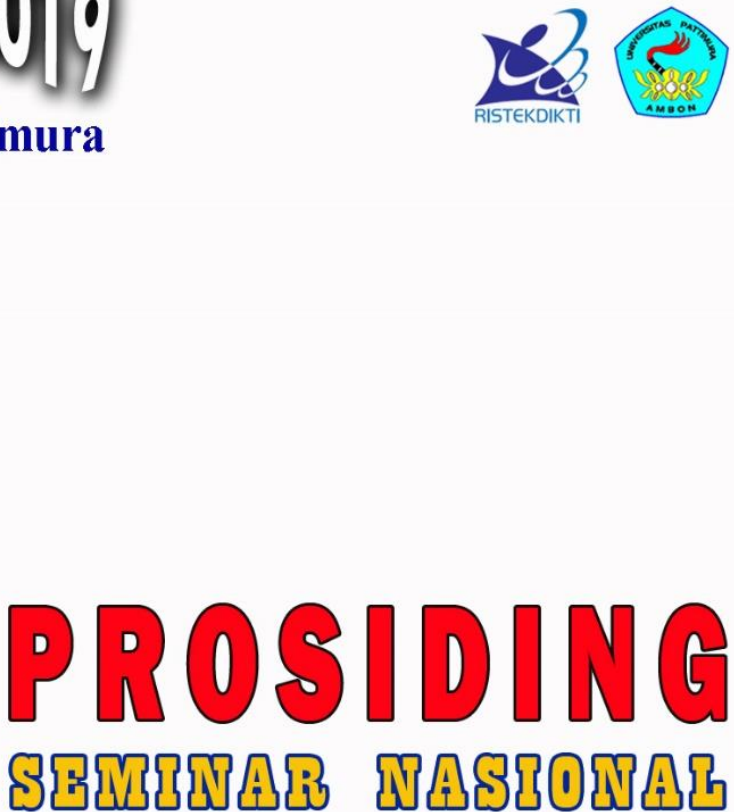

FAKULTASTEKNIK UNIVERSITAS PATTIMURA

KAMPUS POKA AMBON 10 APRIL 2019

Berbenah dalam Tantangan Revolusi Industri 4.0 di Bidang Teknologi Kelautan-Kepulauan Menuju Tahun Emas 2020

FAKULTAS TEKNIK

UNIVERSITAS PATTIMURA

AMBON

2019 


\section{SAMBUTAN DEKAN FAKULTAS TEKNIK UNPATTI}

Assalamulaikum Warohmatullahi Wabarakatuh,

Salam Sejahtera.

Marilah kita panjatkan puji syukur kepada Tuhan Yang Maha Kuasa yang telah memberikan rahmat dan karuniaNya sehingga kegiatan Seminar Nasional ke -2 Archipelago Engineering 2019 dengan tema "BERBENAH DALAM TANTANGAN REVOLUSI INDUSTRI 4.0 DI BIDANG TEKNOLOGI KELAUTAN KEPULAUAN MENUJU TAHUN EMAS 2020" dapat terselenggara dengan baik dan lancar.

Atas nama Keluarga Besar Fakultas Teknik Unpatti, perkenankan saya menyampaikan Selamat Datang di Kampus Fakultas Teknik kepada Bapak Prof. Adi Suryosatyo dari Universitas Indonesia, Bapak Dr. I Made Ariana, ST., MT. dari ITS dan dan Ibu Cathy Garden dari Selandia Baru sebagai Keynote Speakers, para pemakalah dan peserta dari luar Universitas Pattimura guna mengikuti seminar ini.

Saya menyambut gembira karena kegiatan Seminar ALE 2019 ini mendapatkan perhatian yang besar dari para dosen di lingkup Fakultas Teknik Unpatti sehingga lebih dari 40 makalah akan dipresentasikan dalam seminar ini. Untuk itu, saya menyampaikan terima kasih dan penghargaan yang setinggi-tingginya kepada Bapak dan Ibu para pemakalah. Saya yakin bahwa dari seminar ini akan menghasilkan ide-ide, konsepkonsep, teknik-teknik dan terobosan-terobosan baru yang inovatif dan bersinergi dengan pengembangan pola Ilmiah Pokok Unpatti terutama di bidang Kelautan Kepulauan.

Seminar ini terselenggara dengan baik karena dukungan dari berbagai pihak, khususnya para sponsor dan kontribusi dari pemakalah dan peserta. Untuk itu, saya menyampaikan terima kasih yang sebesarbesarnya.

Secara khusus, saya menyampaikan terima kasih dan penghargaan yang setinggi-tingginya kepada Panitia Penyelenggara atas jerih payah, kerja keras, ketekunan dan kesabarannya dalam mempersiapkan dan menyelenggarakan seminar ini sehingga dapat berjalan baik, lancar dan sukses.

Akhirnya, melalui seminar ini, marilah kita senantiasa perkuat dan perluas jejaring serta kerjasama antar sesama dosen sebagai pendidik, peneliti dan pengabdi kepada masyarakat dalam mewujudkan Tri Dharma Perguruan Tinggi guna membangun bangsa dan negara tercinta.

Ambon, 10 April 2019

Dekan Fakultas Teknik Unpatti,

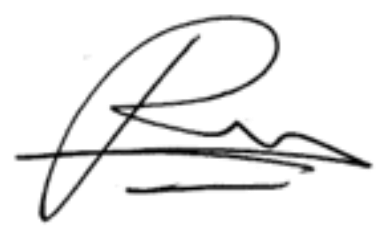

Dr. Ir. W. R. Hetharia, M.App.Sc 


\section{SUSUNAN PANITIA PELAKSANA 2019}

Dr. Novitha L. Th. Thenu, ST., MT

Nikolaus Titahelu, ST, MT

Dr. Debby R. Lekatompessy, ST., MT

Ir. W. M. E. Wattimena, MSc

Danny Pailin Bunga, ST, MT

Ir. Latuhorte Wattimury, MT

N. Maruanaya, SH

Ir. H. C. Ririmasse, MT

Ir. John Latuny, MT, PhD

SEKSI SEMINAR ALE 2019

W. M. Rumaherang, ST., MSc, PhD

D. S. Pelupessy, ST, MSc, PhD

Prayitno Ciptoadi, ST, MT Benjamin G. Tentua, ST, MT

Mercy Pattiapon, ST, MT Meidy Kempa, ST, MT 
HALAMAN JUDUL

Teknik Perkapalan, Teknik Transportasi Laut

E. R. de FRETES :

Analisa Parametrik Channel Flow pada Lambung Kapal Cepat untuk Memperoleh Wake Maksimum. Studi Kasus: Kapal Cepat Rute Ambon Wayame

SONJA TREISJE A. LEKATOMPESSY:

Pengaruh Variasi Parameter Pengelasan Terhadap Kualitas Hasil Pengelasan

OBED METEKOHY :

Analisa Pengaruh Karakteristik Teknis Desain Terhadap Proses Setting Kapal Pukat

Cincin di Maluku

HELLY S. LAINSAMPUTTY :

Analysis Of Principle Dimension And Shape Of Purse Seiners In Ambon Island

WOLTER R. HETHARIA, A. FENINLAMBIR, J. MATAKUPAN, F. GASPERSZ:

Pengaruh Dimensi Terhadap Parameter Stabilitas Kapal-Kapal Penumpang Kecil

Material FRP

LEKATOMPESSY DEBBY R, SOUMOKIL RUTH P, RIRIMASSE HEDY C. :

Analisa Response Dinamik Pada Sambungan Konstruksi Kapal Kayu Berdasarkan Tipe

Mesin Yang Digunakan

EDWIN MATATULA:

Studi Pemilihan Jenis Alat Angkut Bahan Bakar Minyak Wilayah Kepulauan

MONALISA MANUPUTTY :

Pengaruh Getaran Dan Kebisingan Terhadap Kelelahan Kerja Pada Awak Kapal Ikan

Tipe Pole And Line

\section{Teknik Sistem Perkapalan}

ABDUL HADI, B. G. TENTUA :

Algoritma Simulasi Numerik Getaran Dirrect Inline Harmonical Cam Follower Pada

Valve Train Manifold Motor Diesel

DANNY S. PELUPESSY :

Studi Karakteristik Momen Torsi Akumulator Pegas Untuk Penggerak Langkah (StepDrives)

JACOB D. C. SIHASALE, JERRY R. LEATEMIA :

Analisis Penampatan Lokasi Station AIS (Automatic Identification Sistem) Di Ambon

Guna Mendukung Monitoring ALKI (Alur Laut Kepulauan Indonesia) III Secara

Maksimal

LATUHORTE WATTIMURY :

Tinjauan Analisa Kerja Signal AF dan RF Terhadap Kinerja Peralatan Pemancar Dan

Penerima Stasiun Radio Pantai Distrik Navigasi Ambon

MESAK FRITS NOYA, ABDUL HADI :

Studi Eksperimental Pengaruh Posisi Pengelasan Terhadap Sifat Mekanis Baja Karbon

Rendah 
NOVITHA L. TH. THENU :

Pemisahan Sinyal Bunyi Dari Microphone Array Dengan Menggunakan Metode Blind

Source Separation - Independent Component Analysis Untuk Memantau Kondisi Poros

Retak

PRAYITNO CIPTOADI :

Pengaruh Variasi Diameter Pipa Isap Terhadap Karakteristik Pompa Sentrifugal

Teknik Mesin, Teknik Informatika, Teknik Elektro

ANTONI SIMANJUNTAK, JOHANIS LEKALETTE :

PLTS di Pulau Osi dan Permasalahannya

BENJAMIN GOLFIN TENTUA, ARTHUR YANNY LEIWAKABESSY :

Studi Eksperimental Sifat Mekanis Tarik dan Bending Komposit Serat Empulur Sagu

JANDRI LOUHENAPESY, SEFNAT J. ETWAN SARWUNA :

Analisa Kinerja Rem Cakera Akibat Modifikasi Kaliper Roda Belakang Terhadap

Keselamatan Pengendara Sepeda Motor

NICOLAS TITAHELU, CENDY S. E. TUPAMAHU:

Analisis Pengaruh Masukan Panas pada Oven Pengering Bunga Cengkeh Terhadap

Karakteristik Perpindahan Panas Konveksi Paksa

W. M. RUMAHERANG :

Evaluasi Karakteristik Energy Torque Converter Berdasarkan Pengaruh Rasio Putaran

Terhadap Koefesien Torsi dan Efesiensi

ELVERY B. JOHANNES :

Indexing pada Sistem Penalaran Berbasis Kasus Menggunakan Metode Complete-

Linkage Clustering

SAMY J. LITILOLY, NICOLAS TITAHELU :

Laser Semikonduktor GaAs Jenis Double Heterojunction Sebagai Sumber Cahaya dalam Komunikasi Optik

\section{Teknik Industri}

ALFREDO TUTUHATUNEWA :

Model Agile Supply Chain Industri Perikanan di Kota Ambon

AMINAH SOLEMAN :

Analisis Beban Kerja Mental Dan Fisik Karyawan Pada Lantai Produksi Dengan

Metode Nasa-Tlx Dan Cardiovascularload

DANIEL B. PAILLIN, JOHAN M TUPAN, RIZKI ANGGRAENI UTAMI PUTRI :

Penerapan Algoritma Differential Evolution untuk Penyelesaian Permasalahan

Capacitated Vehicle Routing Problem (CVRP). (Studi Kasus: PT. Paris Jaya Mandiri)

MARCY L. PATTIAPON, NIL EDWIN MAITIMU :

Perencanaan Produksi Kerajinan Kulit Kerang Mutiara dengan Menggunakan Metode

Agregat di Kota Ambon

J. M. TUPAN :

Desain Pemasaran Online Berbasis Web untuk Pemasaran Produk Kerajinan Kerang

Mutiara di Kota Ambon. (Studi Kasus: Pondok Mutiara)

NIL EDWIN MAITIMU, MARCY L. PATTIAPON :

Penerapan Economic Order Quantity (EOQ) Guna Menganalisa Pengendalian

Persediaan Bahan Baku Daging Buah Pala pada Usaha Kecil Menengah (UKM) Hunilai di Dusun Toisapu Desa Hutumuri

RICHARD A. de FRETES :

Pengembangan Komunitas Pesisir Di Kecamatan Leitimur Selatan dengan

Memanfaatkan Kearifan Lokal 
MOHAMMAD THEZAR AFIFUDIN, ARIVIANA LIENTJE KAKERISSA :

Aplikasi Pendekatan N-Stage untuk Masalah Pengrutean dan Penjadwalan TrukTunggal di Daerah Kepulauan. (Studi Kasus pada Koperasi Unit Bersama Negeri Booi, Saparua)

W. LATUNY :

Memprediksi Harga Jual Rumput Laut Kering Pada Tingkat Petani Dengan Data Mining

IMELDA CH. POCERATU :

Implementasi Ekoteologi dalam Pencegahan Pencemaran Lingkungan Laut di Pasar Arumbai Ambon

Teknik Sipil, Perencanaan Wilayah \& Kota

A. KALALIMBONG :

Tinjauan Hasil Peningkatan Saluran Suplesi Geren Meten Pulau Buru

S. G. M. AMAHEKA, FUAD H. OHORELLA, JESICA NAHUMURY :

Analisis Biaya Operasnal Kendaraan di Kota Ambon

MEIDY KEMPA :

Kajian Tentang Faktor-Faktor yang Mempengaruhi Keterlambatan Proyek Gedung di

Kota Ambon : Peringkat Faktor \& Solusi Penanggulangannya

SAMMYLES G. M. AMAHEKA, ARIVIANA L. KAKERISSA:

Pengaruh Penerapan Keselamatan Dan Kesehatan Kerja Terhadap Biaya Proyek

Konstruksi Bangunan Gedung di Kota Ambon

PIETER TH. BERHITU :

Model Stuktural Aspek Peran Zonasi dan Masyarakat dalam Pengelolaan Pesisir Kota

Ambon Berkelanjutan

\section{Tambahan}

RIKHARD UFIE, ROY R. LEKATOMPESSY, ZICO MARLISSA:

Kaji Kapasitas Pendinginan Ikan dengan Menggunakan Es dalam Kemasan Plastik

FELLA GASPERSZ, ABDUL DJABAR TIANOTAK, RUTH P. SOUMOKIL:

Kajian Kualitas Kelas Awet Limbah Batang Kulit Pohon Sagu Sebagai Material Alternatif Bangunan Kapal

ABDUL DJABAR TIANOTAK, H. C. RIRIMASSE, ELVERY B. JOHANNES:

Uji Kelayakan Ekonomis Pengembangan Fasilitas Bongkar Muat dan Turun Naiknya Penumpang di Pelabuhan Hurnala Maluku Tengah

H. C. RIRIMASSE, ABD. DJABAR TIANOTAK, ELVERY B. JOHANNES :

Penentuan Sistim Trasportasi Unggulan Di Kawasan Pengembangan Ekonomi

Terpadu (Kapet) Seram Provinsi Maluku

BILLY J. CAMERLING :

Pemilihan Alternatif Bahan Bakar Mesin Pembangkit PLTD Menggunakan Metode Value Engineering 
Kelompak Bidana Kaiian:

TEKNIIK PERIKAPALAN TEKNIIK TRANSPORT'ASI LAUT' 


\title{
ANALISA RESPONSE DINAMIK PADA SAMBUNGAN KONSTRUKSI KAPAL KAYU BERDASARKAN TIPE MESIN YANG DIGUNAKAN
}

\author{
Lekatompessy Debby R. ${ }^{1)}$, Soumokil Ruth P. ${ }^{2)}$, Ririmasse Hedy C. ${ }^{3)}$ \\ e-mail: ${ }^{1)}$ de.lekatompessy@gmail.com \\ ${ }^{1,2,3)}$ Jurusan Teknik Perkapalan, Fakultas Teknik Universitas Pattimura, Ambon 97233, Indonesia.
}

\begin{abstract}
ABSTRAK
Bentuk kapal tradisional di Maluku berubah menurut perkembangan jaman dimulai dengan adanya gosepa yang serupa dengan rakit, kole-kole, kemudian perahu semang atau ketinting, kora-kora, perahu belang dan rurehe. Semua kapal ini tidak menggunakan mesin sebagai tenaga penggerak melainkan masih menggunakan tenaga manusia maupun angin. Jaman sekarang penggunaan mesin sebagai tenaga penggerak kapal sudah banyak digunakan agar radius berlayar menjadi lebih jauh. Efek penggunaan mesin menyebabkan kondisi struktur harus lebih diperhatikan dari sisi keselamatan dan kenyamanannya.

Sumber eksitasi utama pada kapal kayu tradisional bermesin adalah getaran mesin induk. Struktur dirancang untuk dapat menahan beban dari gaya-gaya yang bekerja padanya. Tipe mesin yang digunakan di Maluku kebanyakan adalah tipe mesin dari China dikarenakan harganya yang lebih terjangkau.

Agar getaran mesin induk dapat terdistribusi merata maka karakteristik konstruksi di daerah sambungan harus diketahui agar transmisi bisa direkayasa dan resonansi pada titik tertentu dapat dihindari.

Penelitian ini ingin membuktikan bahwa resonansi lokal dapat diatasi dengan menggunakan bantuan simulasi. Metode Non Destructive Analysis (NDE) banyak digunakan oleh para peneliti terbukti murah, efisien dan efektif untuk struktur yang besar dengan tingkat akurasi yang baik.

Sumber eksitasi berasal dari dua mesin yang berbeda yang dipasang pada kapal dengan ukuran yang sama. Penggunaan dua mesin berbeda bertujuan agar analisa mampu merekomendasikan sambungan yang sesuai dengan performa masingmasing mesin melalui besarnya amplitude yang terjadi dititik-titik sambungan. Perhitungan analitik dilakukan untuk keperluan validasi simulasi.

Analisa konsentrasi tegangan pada masing-masing mesin berbeda. Hasil response struktur akibat eksitasi mesin Yanmar dilakukan juga pada mesin Dong Feng dengan bantuan simulasi bagian yang sama.
\end{abstract}

Kata Kunci: karakteristik getaran, eksitasi, sambungan, resonansi, amplitude

\section{PENDAHULUAN}

Penggunaan kapal kayu tradisional di Maluku masih menjadi pilihan bagi masyarakat pesisir. Penggunaan mesin sebagai tenaga penggerak mulai giat digunakan dikarenakan tuntutan kebutuhan persaingan bisnis yang tidak dapat dihindari. Upaya peningkatan penghasilan tentunya diikuti dengan bertambahnya nilai risiko. Penggunaan mesin harus disertai peningkatan faktor keamanan pada saat beroperasi. Getaran dari mesin dapat merusak konstruksi kapal jika tidak diperhitungkan kemampuannya dalam menerima beban dinamis.

Penentuan sumber getaran, adalah penting untuk menetapkan frekuensi eksitasi dan untuk menghubungkan frekuensi eksitasi dengan frekuensi rotasi poros, dengan menentukan jumlah osilasi per revolusi poros (Yucel and Arpaci 2013). Faktor keselamatan, keandalan dan kontrol kualitas menjadi hal yang sangat penting untuk dipertimbangkan dan tidak dapat dihindari. Karena itu, perlu dilakukan pengembangan teknik analisis dan teknologi pengukuran karakterisasi material (Tan et al. 2011). Kayu tergolong dalam material orthotrop karena memiliki sifat yang unik. Sifat mekanik kayu menjadi perhatian khusus dari Dugdale (1984) melalui eksperimen dengan menggunakan modulus young dan poisson's ratio.

Salah satu karakteristik suatu material yang penting adalah nilai kekakuannya (Soegihardjo and Suhardjono 2013; Lin et al. 2009). Peningkatan kekakuan suatu struktur akan berpengaruh terhadap distribusi getaran yang terjadi terhadap suatu sistem. Pada kapal kayu, beban dinamis dan statik dialami secara bersamaan. Craik and Galbrun (2005) telah melakukan analisa mengenai sambungan dan pengancingan pada konstruksi bangunan kayu. Sedangkan analisa getaran pada pondasi mesin di kapal kayu telah dilakukan oleh Lekatompessy, (2005) dengan melakukan eksperimen dimana ukuran kanal pondasi tidak dirubah hanya nilai $c$ yang di variasi.

Peredam karet dengan ketebalan hasil perhitungan dipasang pada pondasi kapal kayu dan analisa titik pengancingan pondasi ke balok pondasi 2, 3 dan 4 titik (Lekatompessy et al. 2013) untuk memperbaiki distribusi beban akibat getaran mesin ke struktur. Perbaikan sambungan pada kayu mempunyai pengaruh pada nilai kekakuan sistem pengikatan dikarenakan sifat mekaniknya seperti dilakukan oleh Lekatompessy et al. (2017a) 
Karakteristik getaran akibat pengaruh model sambungan, alat sambung dan arah serat juga telah diteliti oleh Lekatompessy et al. (2017b) Mesin yang digunakan memiliki andil dalam mengurangi besar amplitude yang terjadi pada kapal. Sumber eksitasi dua mesin dibandingkan, dimana jenis sambungan kayu bergantung pada besarnya amplitude yang terjadi dan titik-titik kritis.

Kontribusinya pada pembangunan adalah peningkatan keselamatan dan kenyamanan atau pengurangan tingkat resiko kecelakaan di laut akibat kerusakan struktur yang diakibatkan beban dinamis. Jika digunakan dalam tahap perancangan maka dapat menambah umur operasional konstruksi kapal kayu yang tentunya akan menguntungkan si pemilik kapal.

Karakteristik getaran menolong dalam upaya mengurangi dampak buruk getaran yang terjadi terhadap kekuatan struktur. Penelitian ini memperhatikan daerah kritis dimana titik resonansi dapat dihindari jika diketahui besarnya eksitasi dari sumber getar.

\section{KAJIAN TEORI DAN METODE}

Kayu yang digunakan pada penelitian ini adalah kayu Gofasa (vitex cofassus). Kayu ini banyak digunakan untuk material pembangunan kapal tradisional di Maluku. Kayu Gofasa bertumbuh baik pada daerah berkapur dan masih lebih mudah ditemui dibandingkan dengan kayu Jati. Kayu tergolong material orthotrop yang dalam menganalisis sifat mekanik memerlukan metode yang berbeda dengan jenis material isotrop. Data teknis kayu ini diperoleh dari hasil penelitian sebelum.

Model dibuat dengan input data teknis kayu Gofasa dalam proses simulasi. Arah serat kayu yang di analisis adalah arah serat radial dan tangensial. Alat sambung yang digunakan adalah baut, paku dan pasak. Model sambungan adalah model takik miring, takik miring berkait, takik lurus dan takik lurus berkait. Analisis getaran dilakukan pada bagian konstruksi kamar mesin. Response harmonik diperoleh dengan bantuan simulasi.

\section{HASIL DAN PEMBAHASAN}

\section{Proses Rekomendasi Model Simulasi Kamar Mesin Kapal Kayu}

Model simulasi yang dibuat berdasarkan variasi arah serat, alat sambung dan model sambungan. Model simulasi yang direkomendasikan ada 2 model yaitu dari arah serat $\mathrm{R}$ dan $\mathrm{T}$ masing-masing 1 model dari 24 model menggunakan sambungan dan 2 model tanpa sambungan.

\section{Rekomendasi Model Simulasi dalam Arah Serat Radial}

Berdasarkan hasil analisis parameter getaran maka model takik lurus alat sambung paku terbaik untuk arah serat Radial. Pada model ini amplitude yang terjadi sebesar $0,0349 \mathrm{~mm}$ terkecil dibandingkan dengan nilai amplitude pada model dan alat sambung lainnya. (lihat Tabel 1).

Tabel 1. Parameter Getaran Arah Serat Radial

\begin{tabular}{|c|c|c|c|c|c|c|c|c|c|}
\hline \multirow{3}{*}{$\begin{array}{l}\text { connection } \\
\text { tools }\end{array}$} & \multirow{3}{*}{ Model } & \multicolumn{8}{|c|}{ Horizontal } \\
\hline & & \multicolumn{8}{|c|}{ Radial } \\
\hline & & $\omega_{0}(H z)$ & $\%$ & $\mathrm{a}(\mathrm{mm} / \mathrm{N}) \mathrm{k}(\mathrm{N} / \mathrm{mm})$ & $\xi$ & $\%$ & $F_{T R}(\mathrm{~N})$ & $\mathrm{TR}$ & $\%$ \\
\hline \multirow{4}{*}{ Bolt } & $I$ & 41,9 & $53,7 \%$ & $3,76, \mathrm{E}-05 \quad 2,66 \mathrm{E}+04$ & 0,024 & $35,0 \%$ & 16949 & 1,349 & $1,3 \%$ \\
\hline & II & 37,2 & $36,6 \%$ & $6,58, \mathrm{E}-06 \quad 1,52 \mathrm{E}+05$ & 0,027 & $26,8 \%$ & 16897 & 1,345 & $1,0 \%$ \\
\hline & III & 40,7 & $49,2 \%$ & $3,13, E-05 \quad 3,20 E+04$ & 0,025 & $33,0 \%$ & 16937 & 1,348 & $1,3 \%$ \\
\hline & IV & 40,9 & $50,0 \%$ & 1,16,E-05 8,63E+04 & 0,024 & $33,3 \%$ & 16939 & 1,348 & $1,3 \%$ \\
\hline \multirow{4}{*}{ Nail } & $I$ & 39,7 & $45,5 \%$ & 1,09,E-05 9,20E+04 & 0,025 & $31,3 \%$ & 16926 & 1,347 & $1,2 \%$ \\
\hline & II & 39,4 & $44,7 \%$ & 9,01,E-06 1,11E+05 & 0,025 & $30,9 \%$ & 16923 & 1,347 & $1,2 \%$ \\
\hline & III & 39,4 & $44,5 \%$ & $4,02, \mathrm{E}-06 \quad 2,49 \mathrm{E}+05$ & 0,025 & $30,8 \%$ & 16923 & 1,347 & $1,2 \%$ \\
\hline & IV & 39,1 & $43,5 \%$ & 1,87,E-05 5,36E+04 & 0,026 & $30,3 \%$ & 16920 & 1,346 & $1,2 \%$ \\
\hline \multirow{4}{*}{ Peg } & 1 & 35,5 & $30,1 \%$ & $3,23, \mathrm{E}-05 \quad 3,10 \mathrm{E}+04$ & 0,028 & $23,1 \%$ & 16874 & 1,343 & $0,9 \%$ \\
\hline & II & 35,9 & $31,6 \%$ & 1,87,E-05 5,36E+04 & 0,028 & $24,0 \%$ & 16880 & 1,343 & $0,9 \%$ \\
\hline & III & 34,0 & $24,8 \%$ & $5,15, \mathrm{E}-04 \quad 1,94 \mathrm{E}+03$ & 0,029 & $19,9 \%$ & 16853 & 1,341 & $0,8 \%$ \\
\hline & IV & 34,5 & $26,5 \%$ & 1,42,E-05 7,05E+04 & 0,029 & $21,0 \%$ & 16860 & 1,342 & $0,8 \%$ \\
\hline No Joint & & 27,3 & & $3,06, \mathrm{E}-05 \quad 3,06 \mathrm{E}-05$ & 0,037 & & 16727 & 1,331 & \\
\hline
\end{tabular}




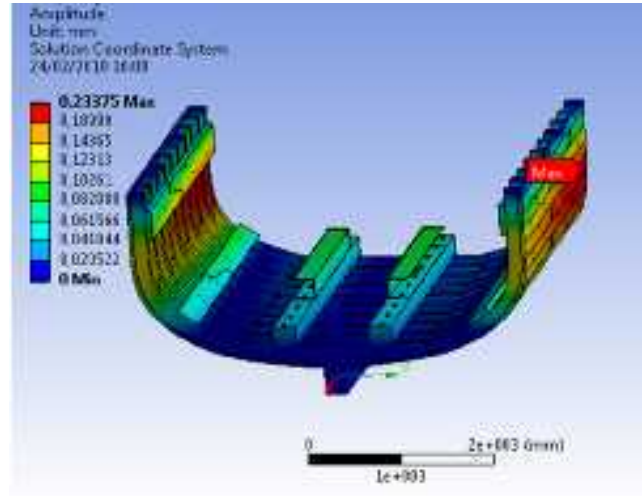

Gambar 1. Response Struktur Model III Takik Lurus menggunakan Alat Sambung Paku Arah Serat Radial dan Deformasi Horisontal (Mesin Yanmar)

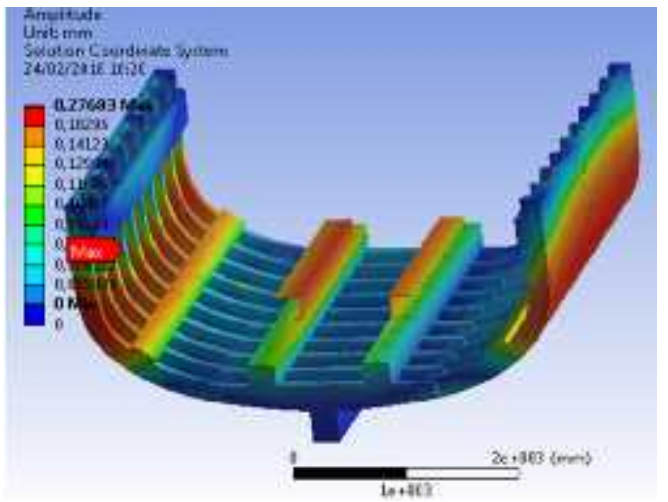

Gambar 2. Response Struktur Model III Takik Lurus menggunakan Alat Sambung Paku Arah Serat Radial dan Deformasi Horisontal (Mesin Dong Feng)

Sebagai pembanding hasil response sruktur akibat eksitasi mesin Yanmar maka dilakukan simulasi untuk model yang direkomendasikan pada bagian yang sama. Mesin pembanding yang digunakan yaitu mesin Dong Feng. Berdasarkan hasil analisis parameter getaran maka pada model simulasi menggunakan mesin Dong Feng amplitude yang terjadi sebesar $0,05117 \mathrm{~mm}$ terkecil dibandingkan dengan nilai amplitude pada model dan alat sambung lainnya. Perbandingan nilai amplitude dapat dilihat pada Gambar 3. Rasio transmisi pada mesin Dong Feng kurang dari 1 yang artinya struktur memerlukan isolasi tambahan.

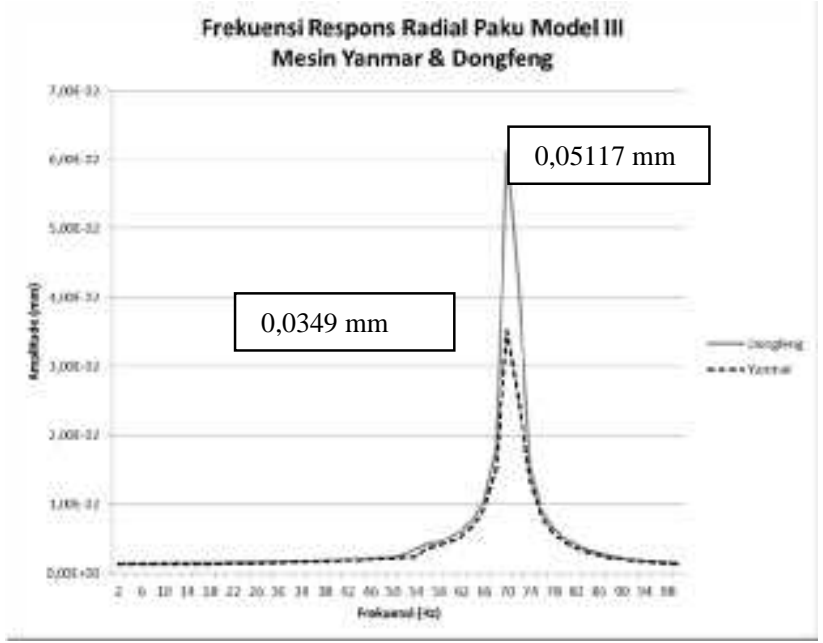

Gambar 3. Grafik Frekuensi Response Struktur Model III Takik Lurus menggunakan Alat Sambung Paku Arah Serat Radial dan Deformasi Horisontal

\section{Rekomendasi Model Simulasi dalam Arah Serat Tangensial}

Berdasarkan hasil analisis parameter getaran maka model II (takik lurus berkait) alat sambung pasak terbaik untuk arah serat Tangensial. Pada model ini amplitude yang terjadi sebesar 0,0175 $\mathrm{mm}$, merupakan yang terkecil bila dibandingkan dengan nilai amplitude pada model dan alat sambung lainnya. (lihat Tabel 2).

Tabel 2. Parameter Getaran Arah Serat Tangensial

\begin{tabular}{|c|c|c|c|c|c|c|c|c|c|}
\hline \multirow{3}{*}{ Model } & \multicolumn{9}{|c|}{ Horisontal } \\
\hline & \multicolumn{9}{|c|}{ Tangential } \\
\hline & $\omega_{0}(H z)$ & $\%$ & $\mathrm{a}(\mathrm{mm} / \mathrm{N})$ & $\mathrm{k}(\mathrm{N} / \mathrm{mm})$ & $\xi$ & $\%$ & $F_{T R}(\mathrm{~N})$ & TR & $\%$ \\
\hline I & 48,4 & $32,8 \%$ & $1,30, E-05$ & $7,72 E+04$ & 0,021 & $24,7 \%$ & 17005 & 1,353 & $0,7 \%$ \\
\hline II & 48,3 & $32,6 \%$ & $1,66, \mathrm{E}-05$ & $6,04 \mathrm{E}+04$ & 0,021 & $24,6 \%$ & 17004 & 1,353 & $0,7 \%$ \\
\hline III & 50,9 & $39,5 \%$ & $5,52, \mathrm{E}-05$ & | $1,81 E+04$ & 0,020 & $28,3 \%$ & 17022 & 1,355 & $0,8 \%$ \\
\hline IV & 47,2 & $29,4 \%$ & $1,01, \mathrm{E}-05$ & $9,95 \mathrm{E}+04$ & 0,021 & $22,7 \%$ & 16996 & 1,352 & $0,6 \%$ \\
\hline I & 50,8 & $39,2 \%$ & $5,92, \mathrm{E}-05$ & | 1,69E+04 & 0,020 & $28,2 \%$ & 17022 & 1,355 & $0,8 \%$ \\
\hline II & 50,7 & $39,1 \%$ & $1,40, \mathrm{E}-04$ & 7,13E+03 & 0,020 & $28,1 \%$ & 17021 & 1,355 & $0,8 \%$ \\
\hline III & 50,7 & $39,1 \%$ & 1,71,E-04 & | 5,84E+03 & 0,020 & $28,1 \%$ & 17021 & 1,355 & $0,8 \%$ \\
\hline IV & 50,0 & $37,1 \%$ & $8,47, \mathrm{E}-05$ & $1,18 \mathrm{E}+04$ & 0,020 & $27,1 \%$ & 17016 & 1,354 & $0,8 \%$ \\
\hline I & 41,2 & $12,9 \%$ & $5,26, \mathrm{E}-05$ & |1,90E+04 & 0,024 & $11,4 \%$ & 16942 & 1,348 & $0,3 \%$ \\
\hline II & 38,0 & $4,3 \%$ & 2,02,E-06 & $4,95 E+05$ & 0,026 & $4,2 \%$ & 16907 & 1,345 & $0,1 \%$ \\
\hline III & 38,4 & $5,4 \%$ & 4,12,E-05 & | 2,43E+04 & 0,026 & $5,2 \%$ & 16912 & 1,346 & $0,1 \%$ \\
\hline \multirow[t]{2}{*}{ IV } & 38,4 & $5,4 \%$ & $5,65, \mathrm{E}-06$ & $1,77 \mathrm{E}+05$ & 0,026 & $5,1 \%$ & 16912 & 1,346 & $0,1 \%$ \\
\hline & 36,5 & & $4,35, \mathrm{E}-06$ & $2,30 E+05$ & 0,027 & & 16887 & 1,344 & \\
\hline
\end{tabular}


Perbandingan antara arah serat radial dan tangensial dapat dilihat pada Gambar 2 dan Gambar 4 yang menunjukkan bahwa model dengan arah serat tangensial memiliki lebih sedikit area kritis dari model dengan menggunakan arah serat radial.

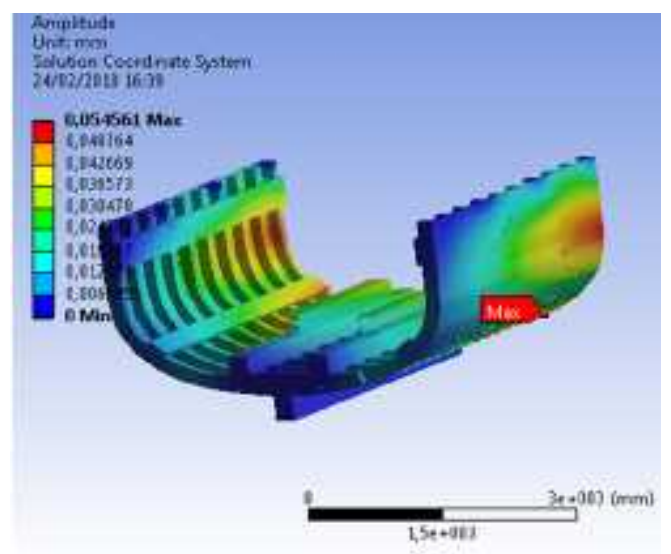

Gambar 4. Response Struktur Model II takik miring berkait menggunakan Alat Sambung Pasak Arah Serat Tangensial dan Deformasi Horisontal

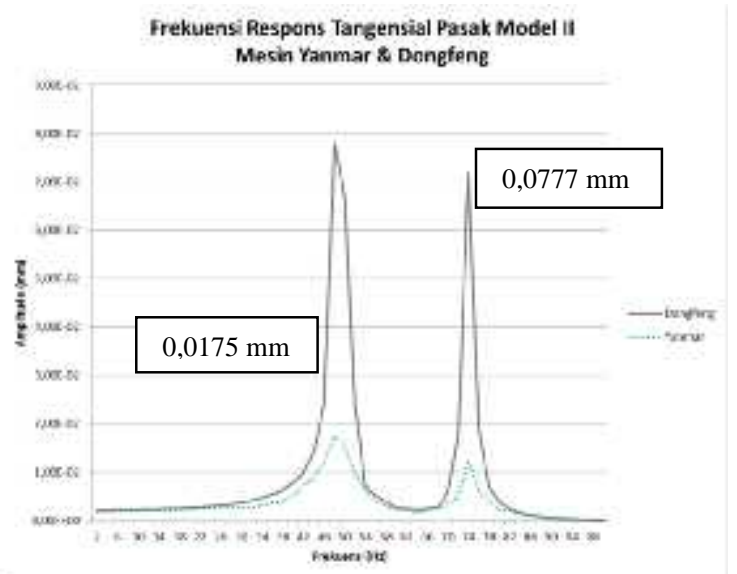

Gambar 5. Grafik Frekuensi Response Struktur Model II takik miring berkait menggunakan Alat Sambung Pasak Arah Serat Tangensial dan Deformasi Horisontal

Sebagai pembanding hasil response sruktur akibat eksitasi mesin Yanmar maka dilakukan simulasi untuk model yang direkomendasikan pada bagian yang sama. Mesin pembanding yang digunakan yaitu mesin Dong Feng. Berdasarkan hasil analisis parameter getaran maka pada model simulasi menggunakan mesin Dong Feng amplitude yang terjadi sebesar $0,0777 \mathrm{~mm}$. Getaran yang terjadi menjadi cukup besar, perbandingan menggunakan dua mesin berbeda dapat dilihat pada Gambar 5. Mesin Dong Feng memiliki nilai amplitude yang besar dibandingkan mesin Yanmar. Harga mesin Dong Feng yang murah menguntungkan dari segi ekonomis tetapi menjadi pilihan yang buruk dari sisi teknis. Rekomendasi yang dibuat untuk kondisi ini adalah jika mesin yang digunakan Dong Feng maka arah serat yang tepat yaitu $\mathrm{R}$ model III takik lurus berkait alat sambung paku dan untuk mesin Yanmar adalah arah serat $\mathrm{T}$ model II takik miring berkait alat sambung pasak.

\section{Batasan Getaran yang Diijinkan untuk Struktur}

Besarnya amplitude yang diijinkan untuk pondasi biasanya ditentukan oleh pabrik pembuat mesin. Amplitude yang diijinkan pada sebuah pondasi mesin ditentukan berdasarkan kepentingan relatif dari mesin dan berdasarkan sifat sensitif dari struktur untuk menerima getaran. Jika data dari pabrik mesin tidak menyertakan besarnya amplitude yang diijinkan, maka nilai-nilai amplitude dapat diperoleh dari hasil observasi Barkan terhadap performance mesin (Tabel 3).

Tabel 3. Amplitude yang Diijinkan

\begin{tabular}{|c|c|}
\hline Type & $\begin{array}{l}\text { Permissible Amplitude } \\
(\mathrm{cm})\end{array}$ \\
\hline Low speed machinery (500 rpm) & $0,02-0,025$ \\
\hline Hammer Fondations & $0,1-0,12$ \\
\hline High Speed machinery & \\
\hline a. $\quad 3000 \mathrm{rpm}$ & \\
\hline - Vertical vibrations & $0,002-0,003$ \\
\hline - Horizontal vibrations & $0,004-0,005$ \\
\hline b. $\quad 1500 \mathrm{rpm}$ & \\
\hline - Vertical vibrations & $0,004-0,006$ \\
\hline - $\quad$ Horizontal vibrations & $0,007-0,009$ \\
\hline
\end{tabular}

Pada mesin dengan kecepatan yang tetap, maka derajat isolasi ditentukan oleh rasio frekuensi $\gamma$ yang didefinisikan sebagai perbandingan antara frekuensi operasi mesin terhadap frekuensi natural pondasi.

Selain itu dikenal pula istilah transmissibilitas, yang didefinisikan sebagai perbandingan gaya yang ditransmisikan ke pondasi terhadap gaya getar yang dihasilkan oleh mesinnya sendiri. Dari teori getaran, transmissibilitas dinyatakan dengan Persamaan 4.4.

$$
\begin{array}{ccc} 
& T=\frac{\sqrt{1+4 \gamma^{2} \xi^{2}}}{(1-\gamma)^{2}+4 \gamma^{2} \xi^{2}} \\
\text { dimana } & \gamma & : \text { rasio frekuensi } \\
& \xi & : \text { faktor damping }
\end{array}
$$

Jika faktor damping sangat kecil sehingga dapat diabaikan, maka dapat ditulis seperti Persamaan 2.

$$
T=\left|\frac{1}{1-\gamma^{2}}\right|=\left|\frac{f_{n}{ }^{2}}{{f_{m}}^{2}-f_{n}^{2}}\right|
$$

Dari hubungan di atas nampak jika harga $\gamma$ yang diperoleh 0,476 lebih kecil dari akar dua $(\gamma<$ $\sqrt{2}$ ) dengan arti tidak terjadi resonansi pada sistem 
walau nilai amplitude berbeda untuk masing-masing mesin.

\section{KESIMPULAN}

Getaran pada kapal kayu tradisional dapat diminimalisir dengan melakukan pemilihan jenis sambungan yang sesuai dengan karakter mesin. Mesin dengan getaran yang besar di frekuensi rendah akan menghasilkan amplitude yang besar pula. Pada penelitian ini mesin Dong Feng memiliki nilai amplitude terkecil masih di $0,078 \mathrm{~mm}$ pada arah serat $\mathrm{T}$ di atas batas amplitude yang diijinkan yaitu $0,04 \mathrm{~mm}$ untuk arah getaran horisontal. Amplitude yang dihasilkan akibat penggunaan mesin Dong Feng akan lebih kecil jika menggunakan model III takik lurus berkait arah serat $\mathrm{R}$ sedangkan mesin Yanmar akan lebih baik jika menggunakan model II arah serat $\mathrm{T}$.

\section{UCAPAN TERIMA KASIH}

Penelitian ini merupakan bagian dari program Beasiswa Nuffic; untuk itu, penulis mengucapkan terimakasih kepada Program Nuffic, Kemenristek Dikti, Universitas Pattimura dan ITS Surabaya, terutama Laboratorium Proses Manufaktur, Teknik Mesin ITS.

\section{DAFTAR PUSTAKA}

Craik, Robert J.M., and Laurent Galbrun. 2005. 'Vibration Transmission through a Frame Typical of Timber-Framed Buildings'. Journal of Sound and Vibration 281 (3): 763-82. https://doi.org/10.1016/j.jsv.2004.02.015.

Dugdale, D.S. 1984. 'Vibration Modes of a Disc of Wood Laminate'. International Journal of Engineering Science 22 (1): 77-86. https://doi.org/10.1016/0020-7225(84)90133-2.

Lekatompessy, D. R. 2005. 'Tinjauan Pengaruh Getaran Mesin Terpasang Terhadap Kekuatan Konstruksi Pondasi Kapal Tradisional'. Jurnal Teknologi 2 (1): 27-35.
Lekatompessy, D. R., I Made Ariana, Achmad Zubaydi, and Erwandi Erwandi. 2017a. 'The Effect of the Fiber of Wood and Connection Tools on the Vibration Characteristics of Gofasa Wood (Vitex Cofassus)'. Research Journal of Applied Sciences, Engineering and Technology $14 \quad$ (7): $242-50$. https://doi.org/DOI:10.19026/rjaset.14.4786.

Lekatompessy, D. R., I. Made Ariana, Achmad Zubaydi, and Erwandi Erwandi. 2017b. 'The Vibration Characteristics of Gofasa Wood (Vitex Cofassus)'. International Review of Mechanical Engineering (IREME) 11 (9): 64450. https://doi.org/10.15866/ireme.v11i9.11636. Lekatompessy, D. R., O. O. Sulaiman, F Manuhutu, E. J. De Lima, and M. Manuputty. 2013. 'Rubber as an Effective Vibration Absorber of Outboard Engine at Small Traditional Fishing Boats from the Human Health and Safety Point of View'. Journal of Engineering Computers \& Applied Sciences 2 (2): 7-12.

Lin, Tian Ran, Jie Pan, Peter J. O'Shea, and Chris K. Mechefske. 2009. 'A Study of Vibration and Vibration Control of Ship Structures'. Marine Structures 22 (4): 730-43. https://doi.org/10.1016/j.marstruc.2009.06.004.

Soegihardjo, Oegik, and Suhardjono. 2013. 'Simulasi Untuk Memprediksi Pengaruh Stiffener Pada Peningkatan Kekakuan Benda Kerja'. Jurnal Teknik Mesin 14 (1): 40-46. https://doi.org/10.9744/jtm.14.1.40-46.

Tan, Mohd Hilman Mohd Akil, N.L.Tajul Lile, F Mat, and S Yaacob. 2011. 'Characterization of Materials by Vibration Technique'. IIUM Engineering Journal $12 \quad$ (3). http://journals.iium.edu.my/ejournal/index.php/i iumej/article/view/143.

Yucel, Adil, and Alaeddin Arpaci. 2013. 'Free and Forced Vibration Analyses of Ship Structures Using the Finite Element Method'. Journal of Marine Science and Technology 18 (3): 32438. https://doi.org/10.1007/s00773-012-0210-1. 